"Nome da música do grupo Comadre Fulozinha utilizada antes da última cena da peça fórum. A letra é a repetição da seguinte frase: "Se queres atirar, atira/Eu também sei atirar".

\section{"Eu também sei atirar"!: Reflexões sobre a Violência contra as Mulheres e Metodologias Estético Políticas}

"I also know how to shoot!": Reflections on Violence against Women and Aesthetic-Political Methodologies

"iYo también sé disparar!": Reflexiones sobre Violencia contra las Mujeres y Metodologías Estético-Políticas

\section{Érika Cecília Soares} Oliveira

Universidade

Estadual Paulista

http://dx.doi.org/10.1590 / $1982-3703000722013$
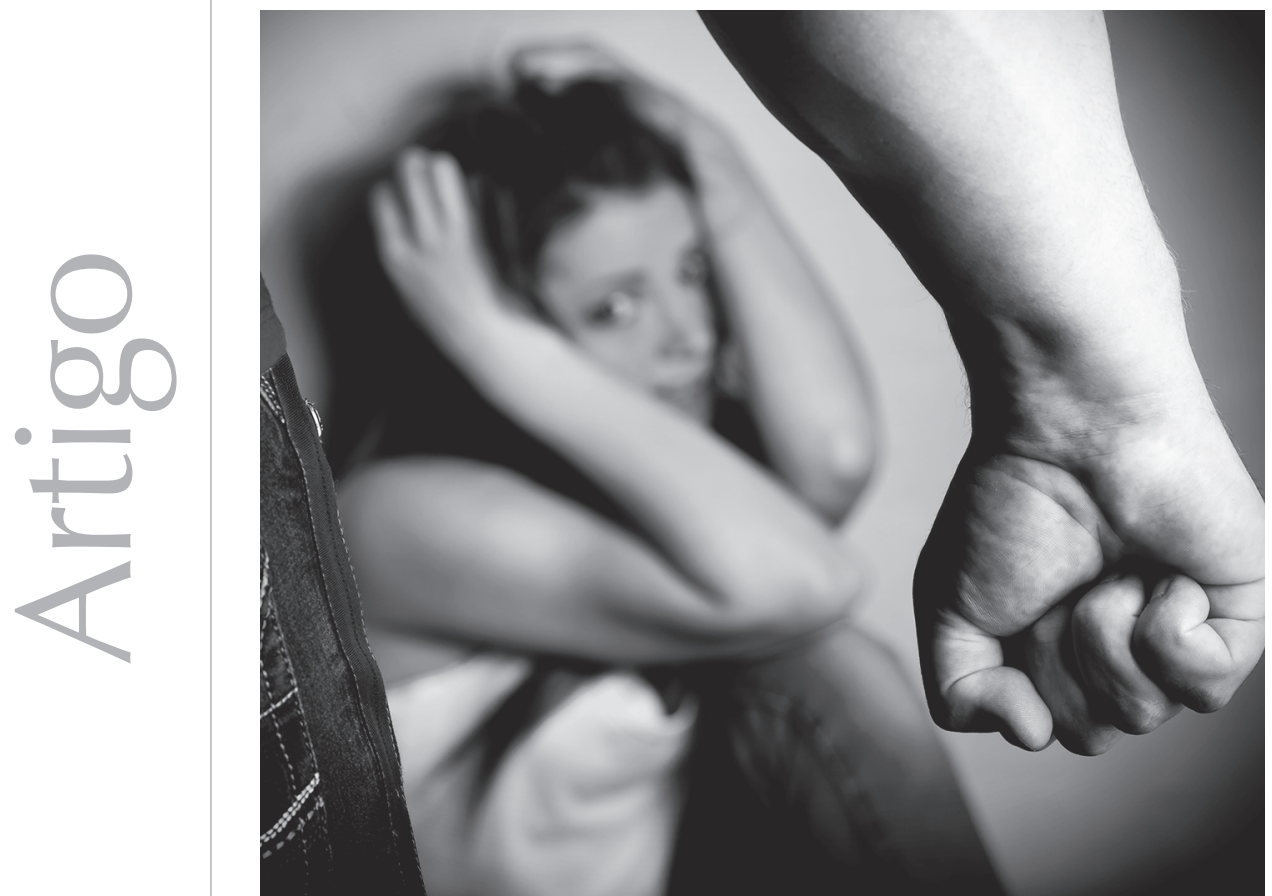
Resumo: Este artigo teve como objetivo fomentar discussões sobre a violência contra as mulheres dentro de uma relação amorosa heterossexual, bem como conhecer discursos sobre gênero, violência, poder, feminilidades e masculinidades dos seguintes grupos de algumas cidades do interior paulista: catadoras e catadores de material reciclável, alunas e alunos de um programa de alfabetização e de um curso profissionalizante e, por fim, profissionais da saúde. A trajetória metodológica empregada também pretendeu inaugurar um novo dispositivo de investigação e intervenção social dentro da Psicologia: o teatro fórum. Foram construídas cenas que mostravam uma protagonista em situação de violência e pediu-se para que as pessoas subissem ao palco e a auxiliassem a resolver aquele impasse. Foram realizadas cinco apresentações para grupos de 10 a 50 participantes entre mulheres e homens. Durante o fórum, surgiram três tipos de discursos que foram nomeados como discursos reguladores, contradiscursos e discursos jurídicos e que mostravam os posicionamentos assumidos pelos(as) falantes na ordem discursiva. Estes foram analisados por meio da análise foucaultiana do discurso. Além disso, foi possível realizar experimentações que tomaram o método do teatro fórum como dispositivo estético e político capaz de produzir debates, questionar regimes de verdade e emancipar sujeitas e sujeitos envolvidos (as).

Palavras-chave: Gênero. Violência contra as mulheres. Teatro. Discurso.

Abstract: This article sought to foster discussions about violence against women in a heterosexual relationship, as well as getting to know discourses on gender, violence, power, femininities and masculinities from the following groups of some cities in the State of São Paulo: pickers of recyclable material, students of a literacy program and of a vocational college, and finally, health-care professionals. The methodological path laid out also intended to inaugurate a new device for research and social intervention within Psychology: Forum Theatre. Scenes were constructed that depict a protagonist in situation of violence and we asked for people to go up to the stage and to help resolve that impasse. Five presentations were held for groups of 10 to 50 participants of both women and men. During the forum, there were three types of speeches that were named as regulating speeches, counter discourse and legal discours, which showed the positions undertaken by (the) speakers in discursive order. These were analyzed though Foucaultian analysis of speech. In addition, it was possible to conduct trials who took the theatre forum method as aesthetic and political device capable of producing debates, question of truth regimes and emancipate involved subjects.

Keywords: Gender. Violence against women. Theatre. Discourse

Resumen: Este artículo tuvo como objetivo fomentar discusiones sobre la violencia contra las mujeres dentro de una relación amorosa heterosexual, así como conocer discursos sobre género, violencia, poder, feminidades y masculinidades de los siguientes grupos de algunas ciudades del interior paulista: recolectoras y recolectores de material reciclable, alumnas y alumnos de un programa de alfabetización y de un curso de formación profesional y, por fin, profesionales de la salud. La trayectoria metodológica empleada también pretendió inaugurar un nuevo dispositivo de investigación e intervención social dentro de la Psicología: el teatro fórum. Fueron construidas escenas que mostraban a una protagonista en situación de violencia y se pidió que las personas subiesen al escenario y la auxiliasen a resolver aquella situación. Fueron realizadas cinco presentaciones para grupos de 10 a 50 participantes entre mujeres y hombres. Durante el fórum, surgieron tres tipos de discursos que fueron nombrados como discursos reguladores, contra-discursos y discursos jurídicos y que mostraban los posicionamientos asumidos por los (las) hablantes en el orden discursivo. Estos fueron analizados por medio del 
*"Esse artigo faz parte da tese intitulada Gênero, violência contra a mulher e Teatro do(a) Oprimido(a): construindo novas possibilidades de pesquisa e intervenção social do programa de pós-graduação em Psicologia, Faculdade de Ciências e Letras, UNESPAssis. Recebeu orientação da Profa Dra. Maria de Fátima Araújo e bolsa da Fundação de Amparo à Pesquisa do Estado de São Paulo (FAPESP).

análisis foucaultiano del discurso. Además de eso, fue posible realizar experimentaciones que tomaron el método del teatro fórum como dispositivo estético y político capaz de producir debates, cuestionar regímenes de verdad y emancipar a los/las sujetos involucrados (as). Palabras clave: Género. Violencia contra las mujeres. Teatro. Discurso.

Neste artigo analiso os resultados de uma pesquisa de doutorado desenvolvida no período de 2009 a 2013* e que teve como objetivo discutir a violência contra as mulheres em relações amorosas ou conjugais heterossexuais junto a grupos de algumas cidades do interior paulista por meio de pequenas cenas de teatro fórum (TF). Articulando pesquisa e intervenção, produção de conhecimento e transformação da realidade objetivou-se refletir o tema junto com a população em geral e conhecer seus discursos sobre gênero, violência conjugal e em parcerias afetivas, poder, casamento, amor, feminilidades e masculinidades, dentre outros e, concomitantemente, investigar se o TF constituiria um instrumento que auxiliaria tanto na pesquisa como na intervenção social podendo integrar o campo da Psicologia e áreas afins. Elegi o TF como instrumento para essa pesquisa por acreditar que essa modalidade permite a participação ativa da plateia, buscando reforçar a autonomia de seus (suas) participantes, colocando-os (as) para agirem, teatralmente, em busca de uma solução para o problema.

A proposta deste artigo é analisar as intervenções da plateia durante e após o fórum, procurando entender o modo como mulheres e homens percebem as posições assumidas pelas mulheres em situação de violência em parcerias afetivas, as saídas sugeridas para a situação da violência e o modo como os autores de violência são contemplados nas intervenções. Pretendo responder questões como: os discursos produzidos pelos (as) espect-atores/atrizes constroem mulheres que se subjetivam por meio de modelos de luta e resistência? Ou, ao contrário, é possível notar discursos que subjetivam as mulheres como devendo se resignar diante dos papéis e nas formas de se relacionarem que lhes foram atribuídos ao longo da história como bem demonstram as pesquisas na área? Como a interiorização dos discursos jurídicos são manejadas e utilizadas pelos (as) participantes para pensarem em estratégias de enfrentamento da violência? Que formas concretas assumem todos esses discursos?

A seguir, farei uma apresentação sobre as concepções utilizadas para entender a violência contra as mulheres em relações amorosas ou conjugais, falarei sobre o uso da legislação e da arena jurídica como espaço de negociações dos conflitos, tensões e violências advindos dessas relações e o modo como a Lei Maria da Penha contribui para a organização de práticas discursivas que referenciam ainda mais o Judiciário como espaço de luta pelos direitos das mulheres, bem como sua aplicabilidade seis anos após sua implantação para, posteriormente, problematizar a prisão do homem autor de violência como uma, dentre as várias medidas que devem ser tomadas quando o assunto é este.

\section{Mulherzinhas reguladas e violência anunciada}

Discutir a violência contra as mulheres implica no exercício de articular diversas teorias e conceitos. Justamente por se tratar de um fenômeno bastante complexo, esse assunto requer que se debruce sobre temas diferentes e, ao mesmo tempo, complementares. É como estar diante de um caleidoscópio que, com suas múltiplas figuras e seus incontáveis arranjos, coloca desenhos diversificados e peculiaridades distintas para se entender $\mathrm{o}$ problema. A partir das descobertas feministas, é possível perceber que a própria definição de "mulher" já contém uma miríade de possibilidades de conceituação, não po- 
dendo ficar fechada em uma explicação única e universal, dado seu caráter escorregadio. Em Manifesto ciborgue, Haraway (2000) demonstra a necessidade de se estabelecer a não inocência da categoria mulher, de entendê-la a partir de sua construção por meio de discursos científicos, sexuais e também de outras práticas sociais questionáveis. A autora convida as feministas a não aceitarem matrizes identitárias naturais e construções que sejam totalidades. Criticando também um "vínculo comum entre todas as mulheres", Bell Hooks (2004) chama a atenção para o fato de que as identidades de raça e classe criam diferenças na qualidade, estilo de vida e status social que se encontram em cima das experiências comuns que as muIheres compartilham, denunciando, assim, o feminismo praticado por mulheres brancas da classe média. Ela aposta na singularidade da experiência das mulheres, entendendo que fatores associados à classe, à raça, à religião, à orientação sexual, dentre outros eixos de diferenciação e poder, favorecem uma diversidade de experiências que acaba por determinar o alcance no qual o sexismo será uma força opressiva na vida de mulheres individuais. Hooks (2004) traz uma importante denúncia sobre o fato de que a análise feminista da situação das mulheres acaba por concentrar-se exclusivamente no gênero, não proporcionando uma fundamentação sólida ao mistificar a realidade das mulheres, insistindo que o gênero é o único determinante do destino delas, sem que se leve em consideração as opressões de raça ou classe ou a interconectividade das opressões.

Avtar Brah (2004) também entende que as estruturas de classe, racismo, gênero e sexualidade não podem ser tratadas como "variáveis independentes" porque a opressão de cada uma está inscrita nas outras, é constituída por e é constitutiva das demais. Assim, para ela, o feminismo negro questiona seriamente qualquer interpretação da mulher como uma categoria unitária e entende como sendo fundamental abordar a questão sobre quais matrizes ideológicas ou campos de significação e representação estão em jogo na formação dos sujeitos além de levar em conta os processos políticos, econômicos e culturais que inscrevem experiências que são historicamente variáveis.

Ao se trabalhar com a categoria gênero para o entendimento da violência contra as mulheres, é preciso assumir que esta ocorre dentro de relações hierárquicas de poder entre mulheres e homens e que não se deve a doenças, problemas mentais, álcool/drogas ou características inatas às pessoas (Meneghel, Bairros, Mueller, Monteiro, Oliveira, \& Collaziol, 2011). A perspectiva de gênero permite, também, que o gênero seja compreendido como o aparato de poder por meio do qual a produção e a normalização do feminino e masculino tomam lugar a partir de formas variadas, construindo verdades e regulações sobre corpos de mulheres e de homens. Não haveria, portanto, uma verdade "interna" da feminilidade considerada como uma disposição psíquica ou núcleo do eu. Para Judith Butler (2002), o gênero não é nem uma verdade psíquica concebida como intrínseca, tampouco pode ser reduzido a uma aparência superficial. Sua condição, ao contrário, deve ser reconhecida como a relação entre psique e aparência e, assim mesmo, essa relação está regulada por restrições heterossexistas. Essas restrições podem ser observadas como demonstra a ex-ministra da Secretaria de Políticas para as Mulheres, Nilcea Freire (2011), ao falar dos desafios assumidos por mulheres que chegam aos espaços institucionais de exercício do poder, questionando, portanto, as expectativas que são direcionadas a elas e que, por isso mesmo, frequentemente são rotuladas como "duronas", "mulherzinhas", "peruas" ou "machonas", sendo que muitas vezes esses adjetivos são utilizados por elas mesmas, como é o caso da própria presidenta da república que afirmou ser uma mulher "dura" no meio de homens "meigos". Para ela, a inclusão das mulheres como sujeitos políticos capazes de interferir na formulação de um amplo conjunto de políticas públicas a partir do exercício de sua cidadania se faz 
mediante o questionamento da lógica do poder, geralmente concentrada nas mãos dos homens. São suas palavras: "Isto porque, no âmbito da gestão pública, o espaço precipuamente destinado às mulheres é frequentemente esvaziado de poder real" (Freire, 2011, p. 138). A ex-ministra, além disso, refere-se ao fato de que a presença de mulheres nesses espaços faz com que sua presença e autoridade sejam frequentemente questionadas, o que confirma o pensamento de Joan Scott (1995) quando diz que a história política é, usualmente, o bastião de resistência à inclusão de questões de gênero e das mulheres. Assim:

A alta política, ela mesma, é um conceito de gênero porque estabelece a sua importância decisiva de seu poder público, as razões de ser e a realidade da existência da sua autoridade superior, precisamente graças à exclusão das mulheres do seu funcionamento. (Scott, 1995, p. 27)

Dentro da normalização do que uma mulher pode esperar de suas relações, a violência surge, muitas vezes implicitamente, como algo que sequer é compreendido como aquilo que realmente é, já que é naturalizada e banalizada pela sociedade. As velhas propagandas de cerveja são exemplo das coerções e regulações de gênero, uma delas, publicizada em 2012, mostra jovens rapazes, brancos, de classe média, procurando um modo de abusar de mulheres sem serem identificados: tomam a cerveja e isso os transforma em homens invisíveis e este poder - de estarem embriagados e de não se responsabilizarem por seus atos - lhes dá a possibilidade de entrar no vestiário feminino e fazer o que bem desejarem, prova disso é a saída das mulheres deste vestiário correndo e aos gritos ${ }^{1}$. Afinal, o que os (as) publicitários (as) que fizeram essa propaganda desejavam, de fato, que a população pensasse e sentisse ao assisti-la? Para combater o fenômeno da violência contra as mulheres é necessário que eventos como esse sejam denunciados e problematizados.

\section{"Eles vão tomar uma providên- cia sobre isso": acessando os direitos por meio de leis}

No Brasil, a violência contra as mulheres tem sido privilegiada pelos movimentos sociais e feministas como pertencente à esfera da justiça criminal e segurança pública, prova disso são as Delegacias de Defesa da Mulher criadas na década de 1980 e, depois, os Juizados Especiais Criminais em meados dos anos 1990, que têm se apresentado como instituições popularizadas e acionadas para a resolução da violência. Para autoras como Leila Barsted (2011), Guita Debert e Maria Filomena Gregori (2008), Maria Cecília Santos (2008) e Lilia Pougy (2010), a revisão das legislações e das instituições do sistema de justiça criminal foi uma aposta política desses movimentos. Voltadas para a defesa das minorias, as delegacias especiais de polícia podem ser vistas como instâncias que expressam a intervenção da esfera política traduzindo, dessa forma, em direitos os interesses daqueles (as) que, de outro modo, não teriam um tratamento justo nos tribunais.

Segundo Débora Maciel (2011), a campanha da Lei Maria da Penha aponta para dois fenômenos sociopolíticos emergentes nas sociedades contemporâneas: o primeiro deles é o uso dos tribunais como estratégia política para grupos e movimentos sociais e a importância dos efeitos ético-políticos das decisões judiciais. Aqui, o uso do direito dá a oportunidade de provocar uma ação responsiva do Estado e de outras autoridades, dramatizando situações sociais problemáticas. O segundo fenômeno demonstra a expansão do direito, em particular do direito penal, como instrumento de resolução de conflito e de mudança social. A apresentação de denúncias ou litígios passa a ser utilizada para politizar ou mesmo para legalizar a política de direitos humanos por meio de casos exemplares. A mudança legal funcionaria como uma alavanca para o acesso às políticas públicas e ao Judiciário. 
Ainda que as discussões em torno da Lei Maria da Penha confiram nova visibilidade ao assunto, ampliando o debate que atinge a população em nível nacional, reconstruindo, assim, práticas e discursos tanto de mulheres como de homens sobre esse assunto, alguns estudos e matérias recentes demonstram que a realidade de sua aplicação ainda carrega resquícios daquilo que tanto se criticava nas delegacias e Juizados Especiais Cíveis e Criminais - JECRIMs (Debert \& Gregori, 2008; Santos, 2008). Em pesquisa realizada com mulheres em situação de violência e operadores (as) de instituições de combate à violência em Porto Alegre, ao discutir a rota crítica percorrida pelas mulheres na tentativa de resolver o conflito, Meneghel et al. (2011) percebem que os três setores mais procurados por elas - policial, jurídico e de saúde - ainda não foram reformulados para sustentar e se implicar na resolução deste problema. Segundo as autoras, nas delegacias, os (as) profissionais continuam focando sua atenção na queixa e na procura apenas do lado criminal, além disso as mulheres entrevistadas relatam entraves tanto na aplicação da Lei Maria da Penha como em deficiências do sistema policial para sua proteção. No setor jurídico, os (as) defensores (as) nem sempre estão por dentro do processo ou sequer conhecem a mulher que irão representar antes da audiência, além de existir muita rotatividade entre eles(as), levando-a a ser atendida por vários(as) profissionais durante o processo. A pesquisa demonstra que elas ainda são levadas a tomar decisões rapidamente na audiência, havendo muita pressão para que reconsiderem a queixa e retornem para suas casas. Os homens autores de violência, por outro lado, são encaminhados para organizações não governamentais, tais como Amor Exigente ou Alcóolicos Anônimos e, o encaminhamento para serviços psicossociais ou de saúde não implica em segurança ou proteção para a mulher, gerando, segundo as autoras a "(...) manutenção de situações de violência e o descrédito, tanto na lei, quanto nos serviços jurídicos e policiais" (Meneghel et al., 2011, p. 748). O setor da saúde, por sua vez, ainda invisibiliza a violência vivenciada pela mulher atendida, encaminhando-a para resolver o problema em outros locais, deixando de se responsabilizar pelo assunto. Ainda que as mulheres desta pesquisa citem a Lei Maria da Penha como um fator facilitador para o combate da violência, parece que os atendimentos que são acionados durante a rota crítica ainda as vulnerabiliza e, muitas vezes, continua a revitimizá-las e essa precariedade dos serviços acaba, muitas vezes, resultando no assassinato dessas mulheres.

Em entrevista realizada em 08/08/2012 para o "Bom dia, Ministro" e disponibilizada pela Agência Patrícia Galvão, a atual ministra da Secretaria de Políticas para as Mulheres, Eleonora Menicucci, falou da importância da rede de atendimento nesses casos, não devendo se resumir apenas às delegacias. Diz ela: "Quando não existe esta rede, as mulheres denunciam e o Estado, o Poder Público, não as acolhe. Elas voltam para casa e, ao fazerem isso, estão voltando para uma situação extremamente perigosa e vulnerável".

Para finalizar este tópico, tomo o artigo publicado na revista Direito e Democracia, da Desembargadora do Tribunal de Justiça do Rio Grande do Sul, Maria Berenice Dias (2006). Nele, ela afirma que a existência de um acompanhamento para o autor de violência (acompanhamento que ela define como "psicológico ou terapêutico") permite à mulher denunciar seu companheiro visando seu direcionamento neste tipo de programa. A desembargadora aposta na denúncia como um caminho para levar o autor de violência para atendimentos nos quais poderá rever suas concepções a respeito da violência que utiliza em sua relação com a parceira, já que ela defende que, muitas vezes, a mulher não quer a separação, dando a entender, em seu texto, que a lei seria um modo de restaurar a harmonia familiar, postura bastante criticada pelas estudiosas do assunto e que corrobora a preocupação diante das posições adotadas pelos (as) operadores (as) do Direito. Diz ela: 
Quando a vítima consegue chegar a uma delegacia para registrar a ocorrência contra alguém que ela ama, com quem convive, é o pai de seus filhos e provê o sustento da família, sua intenção não é de que seja preso. Também não quer a separação. Somente deseja que a agressão cesse. É só por isso que a vítima pede socorro. (Dias, 2006, p. 279, grifo meu)

Vê-se, assim, que a desembargadora concebe a família de acordo com concepções tradicionais: o autor da violência é pai e provedor da família. Para ela, ainda, a mulher em questão quer apenas que os (as) operadores (as) "deem um jeito" em seu companheiro, ela está somente pedindo socorro, não deseja que ele seja preso ou não deseja separar-se dele. Até que ponto essa fórmula pode estender-se para todas as mulheres e será que ela pode, de fato, formar a visão de todos (as) aqueles (as) que ali estão atendendo mulheres em situação de violência? Presumo que esse posicionamento dificulte o acesso das mulheres a um atendimento esclarecedor e eficiente e não permita desconstruções sobre os binarismos tão caros às construções de gênero. Além disso, o tratamento psicológico acaba por ser visto também como outra faceta da pena.

\section{"Mas ele vai ficar longe de você!": a prisão do homem au- tor de violência}

Como outra face da mesma moeda, encontramos como consequência do avanço legal e jurídico e da assunção das mulheres na pauta dos direitos humanos, a punição do autor de violência como consequência e como meio para se coibir atitudes violentas. Reconhecendo a necessidade da responsabilização em casos de violência contra as mulheres, é também significativo o número de autores (as) que acreditam que nem sempre apenas a criminalização é a melhor medida, sendo que cada caso deveria ser analisado em sua singularidade (Beiras, Moraes, Alencar-Rodrigues, \& Cantera, 2012; Medrado \& Méllo, 2008; Oliveira \& Gomes, 2011).
Todos (as) eles (as) apontam para a necessidade de se desconstruir a lógica binária que lança mulheres e homens em duas direções incomunicáveis e que os essencializa em vítimas e agressores/algozes numa postura um tanto maniqueísta como bem adverte Oliveira e Gomes (2011). Essa dicotomia é herdeira, sobretudo, dos estudos iniciais sobre violência contra as mulheres, que compreendiam os homens como detentores exclusivos do poder e os perpetuadores de situações de desigualdade, concebendo, assim, a cultura como algo imutável, fixo (D’Oliveira, 2000). Neste estudo, adotarei o conceito de homem autor de violência, ao invés de "agressor", por entender que o uso dele permite afirmar que os sujeitos envolvidos nesse tipo de situação possuem subjetividades cambiantes, fluidas e propensas a transformações.

Com relação às ponderações realizadas pelos (as) estudiosos (as) sobre esse tema, Benedito Medrado e Ricardo Méllo (2008), assinalam lacunas na lei Maria da Penha, com a finalidade de alcançar compreensões que demonstrem que, enquanto o homem que pratica violência não estiver nas pautas das políticas públicas, dificilmente essa questão atingirá profundamente a sociedade. Para eles, a punição não serviria como medida plena que inquietaria os autores de violência, impedindo-os de agir por medo de sofrerem alguma sanção. Se por um lado é preciso lutar para que as reconstruções das feminilidades e masculinidades não sejam tão rígidas, por outro, é preciso incorporar que a dominação dos homens sobre as mulheres não possui um único autor, sendo construída por diversos (as) autores (as): os homens, as mulheres, a mídia, a religião, a educação e as próprias políticas públicas e instituições sociais.

Cabe lembrar que conhecer a situação dos homens que praticam violência é de vital importância para entender ainda mais as situações de violência contra as mulheres, aprofundar questões e conhecimentos a respeito do poder, autoridade, masculinidade, só para citar alguns, e almejar uma sociedade pautada em princípios éticos em que a violência seja 
cada vez menos utilizada (D’Oliveira, 2000; Oliveira \& Gomes, 2011). Se os discursos jurídicos, tal como ensina Foucault (1997), determinam para os sujeitos que falam, propriedades singulares e papéis preestabelecidos, é necessário então que seja problematizado o modo como esses sujeitos foram construídos historicamente, as coerções experimentadas para que desenvolvessem um tipo específico de masculinidade, recusando, assim, explicações estanques e reducionistas.

\section{Trajetória metodológica}

Exemplificarei a seguir o método empregado para, posteriormente, discorrer sobre o modo como ele foi utilizado na presente pesquisa: por ser caracterizado por seu criador, Augusto Boal (2005), como um "antimodelo", o TF gera um conflito ou drama que é apresentado à plateia por meio de uma pequena cena (esquete) ou peça. Nela, deve existir um (a) antagonista ou opressor (a) e um (a) protagonista ou oprimido (a). A condição básica para sua dramaturgia é que exista um (a) protagonista que deseja livrar-se da opressão que sofre, que procure maneiras um tanto equivocadas para fazê-lo e que, como consequência disso, não consiga. O fórum ou debate se dá justamente nesse momento, com a plateia substituindo-o (a) em cena, colocando-se em seu lugar e tentando resolver seu impasse. Essa capacidade do fórum de suscitar uma pergunta, deixando-a em suspenso, obrigando as pessoas, por meio de sua sabedoria, a buscarem alternativas é, a meu ver, o importante momento em que discursos e práticas podem ser reconstruídos coletivamente e posições subjetivas podem ser perturbadas e, talvez, remanejadas, pois o corpo passa a estar completamente implicado e envolvido na tarefa de colocar-se na pele do (a) outro (a).

O TF é entendido por Boal como um "modelo para a ação futura" e isso se dá pela entrada no palco dos (as) espectadores (as) que se transformam em "espect-atores/atrizes", demonstrando que todo mundo pode ser ator/atriz e estar na plateia ao mesmo tempo e ensaiar ações para o futuro. $\mathrm{O}$ (a) facilitador (a) desse diálogo entre palco/plateia é o (a) curinga, que além de fazer a mediação entre palco e plateia, organiza o espetáculo e coordena o grupo. Aqui, parto do pressuposto de que o TF permite a produção de conhecimento sobre a realidade dos sujeitos pesquisados e, baseada em Donna Haraway (1995), associo a ideia de que esse método pode possibilitar pesquisas posicionadas no campo da Psicologia e nas investigações sobre violência as mulheres. Haraway (1995) defende que somente se produz ciência por meio de uma "postura crítica" do (a) pesquisador (a), acreditando em uma visão objetiva, fundamentada em uma perspectiva parcial e localizada, ela propõe uma relação em que se estabeleçam conversas "nada inocentes" sobre o poder, nas quais se possa perceber, por meio do ponto de vista dos (as) subjugados (as), que eles (as) também não podem escapar das relações de poder, estando sujeitos a desejar, em algumas ocasiões, a posição de dominador (a).

Para elaborar a peça-fórum, formei um grupo composto por estudantes universitários (as) interessados (as) no fazer teatral para discutirmos gênero e violência contra as mulheres, grupo que durante o período de março de 2010 a dezembro de 2011 participou semanalmente de encontros, realizando oficinas de jogos e exercícios teatrais. Junto a isso, realizei capacitações em TF (leitura da obra de Boal, participação em algumas oficinas no Centro de Teatro do Oprimido, dentre outras). Passado um ano, o grupo começou a montar o esquete de TF que viria a receber o nome de "Segura meu coração" e que tinha uma duração média de 10 minutos. Nas três primeiras apresentações, participaram seis atores/atrizes e, ao final de cada cena, a própria protagonista atuava como curinga e convidava alguém da plateia para auxiliá-la a resolver seu conflito. Nas duas últimas apresentações, participaram cinco atores/atrizes e a mediação entre palco e plateia foi realizada por mim. Ainda que as paradas para que as pessoas entrassem no palco 
2. As personagens foram retiradas do livro $\mathrm{O}$ dia dos prodígios da escritora portuguesa Lídia Jorge. fossem definidas por nós, também nessas apresentações finais, as pessoas puderam entrar espontaneamente no palco, bastando manifestar seu desejo para isso.

Para a montagem do esquete foram utilizadas junções de textos de minha autoria e também de outros (as) autores (as) e suas obras. Usualmente, a dramaturgia de um espetáculo de TF é construída pelo próprio grupo, mas, neste caso, a opção de levar textos de outros (as) autores (as) foi uma decisão que visava a assegurar que nascesse dali um texto que produzisse indagações nas pessoas e, ao mesmo tempo, inaugurasse uma linguagem poética, não cotidiana, para se discutir tema tão duro. Como resultado final dessa junção de textos, foi possível construir uma dramaturgia que contemplava uma situação de violência conjugal vivida por Branca e praticada por seu marido, José Pássaro Volante ${ }^{2}$ que trazia a seguinte pergunta: o que vocês fariam se estivessem no lugar da protagonista? Construíram-se três cenas que abordavam a violência sofrida por Branca e a opinião de duas vizinhas que se posicionavam contra a protagonista ou a favor. Na primeira cena, as vizinhas Jesuína e Esperancinha comentam a situação de Branca e Jesuína, que se posiciona a favor de Pássaro, chega a concordar que ele impeça a esposa de sair de casa. Nessa cena, a protagonista também se apresenta para a plateia e conta a todos (as) o seu drama: ela borda uma colcha interminável com um dragão em seu centro. A eficácia de seu trabalho é medida pelo marido que a castiga caso note que as escamas do dragão cresceram. Na segunda cena, Jesuína diz para Esperancinha que não se mete em briga de marido e muIher e que Branca deve saber muito bem por que está apanhando. Ainda nessa cena, Pássaro manifesta seu desejo de ter uma esposa obediente e conta para a plateia como pretende fazer sexo com ela, mesmo contra sua vontade. Na terceira e última cena, Esperancinha, preocupada com a vizinha, diz-lhe para ela sair daquela colcha (e daquela história) e fazer alguma coisa seja com palavra, faca ou tiro.
Foram feitas cinco sessões de TF em três cidades do interior do oeste paulista para os seguintes grupos composto por mulheres e homens com idade igual ou superior a 18 anos: uma cooperativa de material reciclável, uma associação de material reciclável, alunos (as) de um programa de alfabetização para jovens e adultos, alunos(as) de um curso profissionalizante para camareiro(a) e, por fim, para profissionais da saúde. Os grupos variavam entre 10 e 50 pessoas e o critério de escolha foi o pouco acesso que possuíam a intervenções artísticas como essa. As apresentações aconteciam nos locais de trabalho ou estudo dos (as) participantes, sendo que o grupo chegava com antecedência a esses lugares para montar a estrutura que serviria como base para a apresentação do esquete (telão, projetor, filmadora etc.). Antes disso, uma das atrizes fazia contato com os (as) representantes dos grupos que haviam sido escolhidos, agendando reunião para explicar o projeto, combinar horários e dias compatíveis e tudo o que fosse necessário. Além das intervenções realizadas no fórum (isto é, com a entrada dos (as) espect-atores/atrizes no palco), também abri para discussão após as apresentações. Essa abertura, que acontecia posteriormente à encenação e ao fórum, foi cunhada por "roda de conversa" e o tempo médio dos encontros variou entre uma hora e uma hora e meia. O registro dos dados foi feito por meio de gravação e filmagens das falas e/ou imagens dos (as) participantes e, também, em observações feitas por mim no diário de campo. A participação na pesquisa foi espontânea e todos (as) os (as) participantes assinaram o termo de consentimento, conforme Resolução CNS no 196/96.

\section{Análise dos resultados}

No caso deste estudo, foi utilizada a Análise Foucaultiana do Discurso (AFD) para analisar as falas dos (as) participantes durante o fórum ou na roda de conversa. A preocupação da AFD é a linguagem e o papel que ela tem na constituição da vida social e psicológica das pessoas, bem como o papel do discurso em 
processos sociais mais amplos de legitimação e poder, pois parte do pressuposto de que os discursos hegemônicos privilegiam versões sobre a realidade que, por sua vez, legitimam as relações de poder existentes e as estruturas sociais, daí seu foco ser tais relações.

Para Foucault (1997), o discurso não é simplesmente aquilo que traduz as lutas ou os sistemas de dominação, mas aquilo pelo qual, e com o qual se luta, o poder do qual as pessoas querem se apoderar. Assim, é necessário considerá-lo como um jogo estratégico de ação e reação, de perguntas e respostas, de dominação e esquiva (Foucault, 1973). Segundo ele, os discursos são acontecimentos, têm forma de regularidade e sistemas de coerção, possuem materialidade e constituem um conjunto de estratégias que fazem parte das práticas sociais, engendrando domínios de saber que fazem aparecer novos objetos, conceitos e técnicas e também formas inéditas de sujeitos e de subjetividades.

Desse modo, para a análise de um texto é necessário ter em vista quem fala, isto é, o status dos indivíduos que têm o direito de proferir o discurso; os lugares de onde se fala, que implica em compreender os lugares institucionais dos quais as pessoas obtêm seus discursos e, por último, as posições de sujeito, que são definidas pela situação que é possível ocupar em relação aos diversos domínios ou grupos de objetos. É possível, assim, tentar desvelar os regimes de verdade produzidos pelos discursos, já que cada sociedade tem o seu regime ou modelo de verdade, sua "prática geral" de verdade, isto é, os tipos de discursos que ela acolhe e faz funcionar como verdadeiros. Verdade aqui deve ser entendida como o conjunto de regras segundo as quais se distingue o verdadeiro do falso e, se atribui ao verdadeiro, efeitos específicos de poder, desempenhando, portanto, um papel econômico e político (Foucault, 1979). Segundo Foucault (1969/2008), o sujeito que fala não mostra nunca um discurso genuíno, mas constrói seu discurso e sua identidade discursiva por meio de um trabalho de relações.
O que guia esse tipo de análise são as problematizações, isto é, a prática de colocar em dúvida tudo o que está configurado como inquestionável ou indubitável (Iñiguez, 2005a). Nem todos os textos podem ser considerados discursos e nem todos os conjuntos de enunciados podem revelar determinadas posições, sendo que "só o fazem aqueles que possuem valor para uma coletividade, que envolvem crenças e convicções compartilhadas. Ou seja, os textos que claramente incluem um posicionamento em uma estrutura discursiva" (Iñiguez, 2005b, p. 129). Para realizar a análise desse material, foram seguidas as indicações apropriadas para essa pesquisa realizadas por autores (as) como Iñiguez (2005a, 2005b), Parker (1996) e Willig (2008). Assim, o texto foi colocado em linguagem escrita, associando livremente com ele e detalhando sistematicamente os objetos que ali apareceram. Como dispositivo para explorar o direito à fala no seio dos discursos, reconstruiu-se o que cada pessoa tinha a dizer dentro do marco de regras propostas pelo texto, tentando visualizar os direitos e responsabilidades da plateia, suas redes de relações e seus posicionamentos.

\section{Discussões}

Como assinalado anteriormente, interessa aqui analisar os discursos produzidos por meio das intervenções realizadas pelos (as) espect-atores/atrizes durante o fórum, seja por meio de sua entrada no palco e que denominei como teatro fórum (TF) ao longo deste artigo, seja por meio da contribuição que deram sentados(as) em suas cadeiras ou, ainda, no final da apresentação, quando abri para debater o tema e que aqui chamarei, ambas, de roda de conversa (RC). Nesses dois últimos casos, os (as) participantes (as) serão denominados (as) de espectadores (as), por não terem emprestado seu corpo à ação teatral. Os nomes escolhidos para representá-los (as) são fictícios, retirados de livros da literatura escritos por João Guimarães Rosa, Hilda Hilst e Mia Couto. 
Cabe lembrar que, em razão desse espaço ser limitado, foi escolhido um número reduzido de exemplos para ilustrar cada tipo de discurso e que, neste caso, todos são discursos de mulheres. Houve, contudo, participação dos homens durante as apresentações e esta foi discutida em outros lugares. No grupo de profissionais da saúde, por exemplo, alguns chegaram a entrar no palco e substituir as atrizes. A análise desses discursos, em virtude do tipo específico desse grupo, ficou bastante atrelada a reflexões sobre o modo como a violência é enfrentada no contexto da saúde.

\section{Discursos reguladores: entre safadas e santas}

Representando esses discursos, no TF ou $\mathrm{RC}$, aparecem aqueles que apontam a relação entre mulheres e homens permeada por obrigações e papéis tradicionais que devem ser seguidos rigidamente, caso contrário, a mulher é merecedora de violência por parte de seu companheiro. Além desses, há a prevalência de discursos que veiculam a ideia de que muitas mulheres que sofrem violência o fazem por não terem vontade de trabalhar, estarem acomodadas nas relações ou, ainda, por não terem autoestima, autoconfiança ou atitude, promovendo uma verdadeira culpabilização da mulher que vive em situação de violência.

A seguir, um exemplo desse tipo de discurso que foi pronunciado na roda de conversa por Maria Mutema, espect-atriz que entrou no palco várias vezes substituindo Branca e tentando ajudá-la na resolução do conflito e Rosa'uarda que não entrou no palco nenhuma vez, mas que esteve o tempo todo incentivando a protagonista:

Mas existe mulher também que é atentada, viu? Tem mulher atentada, viu? Ruim! [Maria Mutema fala para a colega que está ao seu lado, Rosa'uarda. Continua]: - Não é verdade? (...). Tem mulher pilantra, sem-vergonha, safada, tem muitas que faz cada coisa que eu vejo!
Olha, há 13 anos que eu sou viúva e hoje eu não vejo... tem mulher aí que tem marido, sai bagunçar e larga os filhos em casa, sai bagunçar... e quer que o marido chegue e não meta o cacete! [Rosa'uarda responde]: Tem que bater, essa tem que apanhar" (Maria Mutema e Rosa'uarda, RC, alunas de programa de alfabetização, grifo meu).

No discurso de Maria Mutema e Rosa'uarda, um regime de verdade é construído: mulheres atentadas, pilantras, sem-vergonhas, safadas são aquelas que, tendo marido, saem para bagunçar, deixando filhas e filhos em casa e, ao que tudo indica, ainda esperam que seus maridos não lhes deem um cacete. Esse tipo de mulher, na opinião delas são justamente aquelas que têm que apanhar, que o marido tem que bater. Note-se aí que o verbo ter é usado como um imperativo, uma norma que define, fixa e organiza papéis, pois se existe uma mulher que tem que apanhar é porque existe um homem que tem que lhe bater, havendo, portanto, funções designadas e expectativas distribuídas para a manutenção de papéis tradicionais: mulheres devem cuidar de suas casas, de seus maridos e de seus filhos (as), homens devem corrigir seus excessos. A escolha pelo castigo físico como forma de controlar e coagir a mulher que se desviou da norma é a proposta feita pelas duas. Butler (2005) ensina que as pessoas são reguladas pelo gênero e esse tipo de regulação opera como uma condição de inteligibilidade cultural para elas. Assim, desviar das normas de gênero é produzir o exemplo aberrante que os poderes regulatórios podem explorar rapidamente para apontar a justificativa de seu próprio zelo regulador continuado.

Operando como fenômeno psíquico, a norma restringe e produz o desejo, regendo também a formação do sujeito e circunscrevendo o âmbito da sociabilidade visível. O funcionamento psíquico dela oferece ao poder regulador um caminho mais insidioso do que a coerção explícita e o êxito disso permite seu funcionamento dentro do social 
(Butler, 2010). É possível ver por meio do discurso das espect-atrizes que as normas de gênero às quais Butler (2002) se refere operam exigindo a encarnação de certos ideais de feminilidade e masculinidade que, quase sempre, estão ligados à idealização de uniões heterossexuais.

Dessa maneira e segundo a autora, o enunciado performativo iniciador "É uma menina!" antecipa a sanção "Eu os declaro marido e mulher". Assim, nomear a "menina" é transitivo e inicia o processo pelo qual impõe uma certa "feminização", governada pelo poder simbólico desse termo que toma forma no corpo e que nunca se aproxima, totalmente, da norma. A feminilidade não seria o produto de uma eleição, mas sim da repetição forçosa de uma norma cuja historicidade é inseparável das relações de disciplina, regulação e castigo. O modo como a feminilidade é construída socialmente resulta em uma prática que confere à mulher um lugar tangenciado pelo preconceito dado o caráter natural - e não político - que é conferido à sua existência

Cabe, então, a pergunta: por que mulheres que possuem uma vida não conformada aos preceitos morais - elas bagunçam mereceriam ser espancadas? O desvio ou a bagunça das regras heterossexuais estipuladas dentro das relações as transformariam em mulheres "meramente matáveis" usando expressão de Sandra Azerêdo em conversa com Donna Haraway? (Haraway \& Azêredo, 2011). É interessante e, ao mesmo tempo assustador, constatar que Maria Mutema e Rosa'uarda, cada uma ao seu modo, tentaram auxiliar Branca na cessação da violência vivida por esta, mas é necessário lembrar que essa personagem era uma dona de casa responsável, que cuidava de sua casa e de seu filho, não sendo, portanto, moralmente repreensível. Como seria se a protagonista apresentasse "desvios"? Seria ela defendida pela plateia?

\section{Discursos de resistência ou con- tradiscursos: sobre homens e repolhos}

Os contradiscursos encontrados durante o fórum ou na roda de conversa aparecem principalmente questionando as noções tradicionais de amor, casamento e poder, mostrando a necessidade da partilha e liberdade nas relações, por um lado e, por outro, a necessidade da mulher se colocar frente ao homem em pé de igualdade, mesmo que para isso utilize da violência como forma de cessar os abusos cometidos pelo companheiro. Esse tipo de discurso costuma ser caracterizado por ser polêmico e mostrar um sujeito discursivo que destoa das vozes normativas, caracterizando-se por negações de definições reguladoras, recusa de obrigações etc. (Llombart, 1993).

E ele mesmo [o marido da espectadora] falou pra mim, porque ele não rela a mão em mim, eu falei você não rela mesmo, eu sei que no soco não vou bater em você, mas você vai dormir, na hora em que você dormir eu te "lanho" inteirinho. Só isso, eu faço ele virar um repolho. Sem essa, eu nunca apanhei do meu pai, vou apanhar de macho? (Matamouros, RC, catadora de material reciclável).

No discurso de Matamouros, a violência é tida como intolerável. Como forma de combatê-la, essa espectadora procura soluções que lhe coloquem em uma relação simétrica com seu companheiro. Ainda que não tenha força suficiente para entrar em uma briga "eu sei que no soco não vou bater em você", ela encontra uma estratégia que a coloca em pé de igualdade caso sofra algum tipo de violência dele: espera ele dormir e transforma-o em um repolho, se necessário. A não aceitação da violência se estende para qualquer tipo de homem, seja pai, marido ou substituto dessas figuras que representam a autoridade e o poder de dominação. A es- 
pectadora interpela e polemiza: "sem essa (...) vou apanhar de macho?". Constrói-se, assim, uma nova subjetividade na qual a resistência e a autoafirmação passam a figurar e atuar nas formações discursivas. O gênero assume outra dimensão apontada por Butler (2005): ele é o mecanismo no qual se naturalizam noções de feminilidade e masculinidade, mas também pode ser o aparato mediante o qual tais termos são desconstruídos e desnaturalizados, provocando uma permutação de gênero, uma dúvida sobre os binarismos com os quais se está habituado (a), afinal, essa mulher "lanha", rasga o seu companheiro inteirinho e este deixa de ser um homem e vira um vegetal, atitude pouco esperada em se tratando de uma mulher e quando se pensa nos modos corriqueiros com que a noção de mulher e feminilidade são construídas.

Matamouros foge da norma nesse aspecto, ainda que estar fora da norma signifique ser definido(a) em relação a ela, como demonstra Butler (2005), não ser feminino ou masculino por completo é ser, ainda assim, compreendido(a), exclusivamente, em termos da relação que se tem com esses dois termos. Ela cria uma mulher que não aceita ser tratada como um "ser inumano" ou, ainda, um corpo abjeto (Butler, 2010), sua vida é "digna de valer a pena" (Butler, 2006). A espectadora faz valer, por meio de estratégias, sua igualdade frente ao homem. Abjeção significa literalmente lançar para fora, longe. Se a materialidade do sexo é construída por meio da repetição ritualizada das normas, essa mesma construção produz corpos inteligíveis e corpos abjetos. A noção de abjeto designa um status degradado ou expulso em termos de sociabilidade. Ainda que a igualdade preconizada por Matamouros tenha que brotar por meio da medição de forças e da troca de violências, ela consegue colocar a espectadora como alguém que faz parte do contrato social, cria regras e pautas para o convívio com o outro, faz com que seu corpo seja pensável e, sobretudo, vivível. Mas cabe lançar uma pergunta e não se contentar com uma solução aparente- mente fácil: ainda que existam mulheres que façam uso da violência para se defenderem e até mesmo transgredirem normas de gênero, é possível acreditar que a utilização desse expediente as irresponsabiliza por essa escolha?

Optei por chamar aqui de contradiscurso a transgressão das normas de gênero - mulheres podem ser violentas, mas poderia continuar a chamá-lo assim acreditando que a violência vinda de mulheres provoca linhas de fraturas e inaugura novos arranjos afetivos entre os casais? Acredito que não. Tomo aqui a ideia de Butler (2006) ao avaliar o papel da violência na vida das pessoas e da análise de que, paradoxalmente, o fato de alguém ter sido exposto (a) à violência vinda de outrem aumenta sua responsabilidade perante ela. Alguém que sofre uma violência é eticamente obrigado a perguntar-se como deve responder ao dano sofrido, sobre seu papel frente à manutenção dele, em que se converterá ao respondê-lo de um ou de outro modo e sobre o desejo de se estender ou impedir que a violência se propague pela resposta que se pretende dar. Portanto, ainda que a intenção de Matamouros - a autodefesa - seja legítima e até mesmo compreensível, o modo como escolhe para revidar não lança luz alguma quando o assunto é o enfrentamento da violência e, concomitantemente, a construção de uma sociedade justa e igualitária.

\section{Discursos jurídicos: a produção de seres humanos e inumanos}

De modo geral, esses discursos foram utilizados durante os encontros em um movimento duplo: ora para apontar que a mulher poderia procurar o sistema de justiça como forma de ser protegida e, ao mesmo tempo, conhecer seus direitos, ora como forma de punir o homem autor de violência. Abaixo, colocarei a fala de Ernestina, espect-atriz que nesse momento do Fórum substitui a amiga e vizinha de Branca, Esperancinha e tenta acionar soluções junto à protagonista: 
Cê já pensou em procurar uma delegacia da mulher, denunciar ele? [...]. Vai, pega uma carona, eu sou sua vizinha aqui do lado, eu posso ir com você, eu te acompanho [...]. Você vai dizer [na delegacia] que ele é uma pessoa agressiva, que ele te agride, fisicamente, moralmente e eles vão tomar uma providência sobre isso. [...]. ele vai ter que ficar longe de você ou vão prender ele, mas ele vai ficar longe de você! (Ernestina, TF, aluna de curso técnico).

Para entender a importância dos discursos jurídicos utilizados pela plateia, é preciso lembrar, tal como ensina Foucault (1973), que os discursos são "jogos estratégicos" ou um conjunto de estratégias que fazem parte das práticas sociais e que são justamente as práticas judiciárias as maiores responsáveis por produzir novas formas de subjetividade, de saber e de relações entre os sujeitos e a verdade, já que é a partir delas que certo número de "regras de jogo" são definidas e se estabelecem. Tais práticas, também conhecidas como práticas regulares, são responsáveis pelos "modelos ou regimes de verdade" que circulam nas sociedades, se impõem e valem não somente no campo da política, mas também no campo do cotidiano, tornando-se constitutivas do sujeito. Cada sociedade tem seu "regime de verdade" e é composta por tipos de discursos que acolhe e que funcionam como verdadeiros, isto é, desempenham papéis econômicos e políticos. Cabe, então, tentar entender como a produção de leis e de penalidades alinhava os discursos construídos pelas pessoas sobre o modo de se enfrentar a violência, ora tendendo para discursos em prol da equidade pela via dos direitos, ora na penalização, pura e simples, do homem autor de violência.

Já antes da Lei Maria da Penha ser sancionada, alterações no Código Penal brasileiro, em vigor desde 1940, tentavam revisitar discursos um tanto prescritivos, próprios do sistema penal (Foucault, 1973), que ditavam formas de regularidade e sistemas de coerção sobre as mulheres. Assim, a expressão "mulher honesta" contida nos artigos 215 e 216, por exemplo, foi retirada do Código somente em 2005 (Barsted, 2011). Aqui, o enunciado honesta dava à lei um caráter moralizante e demarcava um certo tipo de conduta que as mulheres deveriam ter, delineando sob quais condições e de acordo com quais comportamentos seriam ou não defendidas pela lei. Seus efeitos discursivos ainda hoje são pulverizados na sociedade por meio de suportes institucionais de tal modo que, em casos de estupro, o passado da vítima é utilizado para se tentar justificar o crime cometido contra ela e a mídia, sobretudo aquela especializada em divulgar pormenorizadamente a condução desses casos para a população, sempre foi um instrumento bastante contundente neste tipo de divulgação. Como reação a isso, é possível ver nos movimentos sociais contemporâneos, como é o caso da Marcha das Vadias, a contraposição do enunciado honesta, pelo que seria então o seu oposto - vadia - e a crítica contida no uso dessa palavra utilizada para denunciar machismos e crimes.

Ernestina traça um plano junto à Branca no qual se disponibiliza a levá-la à delegacia e constrói para ela uma defesa na qual a vizinha e amiga explica que o marido é uma pessoa agressiva, que a agride física e moralmente e, com isso, acredita que uma providência será tomada, seja uma medida protetiva ("ele vai ficar longe de você") ou então a prisão de Pássaro ("ou vão prender ele"). A incorporação da instância jurídica como local de proteção e da violência como um crime passível de punição resulta em um modo de sanar os abusos cometidos pelo homem. Branca é legitimada social e discursivamente a procurar defender-se como um sujeito dotado de direitos.

Convém ressaltar que, conjuntamente com a procura de direitos e proteção, foi possível encontrar, talvez de modo um tanto inevitável, a prisão do autor da violência nos discursos tanto de espect-atrizes como de espectatores. A prisão do autor de violência, é certo, auxilia no entendimento de que a violência é um crime e não deve ser tolerada. Isso não implica, contudo, em dizer que a vida dos autores de violência não seja digna 
de valer a pena e que estes não devam ser humanizados e contemplados nas políticas públicas voltadas para discutir suas masculinidades e a incorporação da violência como um atributo dos homens.

Deste modo, fecho este tópico utilizando dois discursos de Ernestina para mostrar que, no seio de uma contradição sentida por essa espect-atriz, há o germe para se olhar este problema de modo humanizado e ético. Ao tentar convencer Branca a deixar o José Pássaro, ela diz: “(...) ele [José Pássaro] não merece nem ser chamado de homem. Ele merece ser chamado como um animal, um bicho. Os próprios animais às vezes têm carinho, são companheiros de suas fêmeas, e ele não tem [carinho] por você". Depois, na roda de conversa, ela pondera e torna-se a primeira e única espect-atriz a mencionar essa saída:

Por isso até que tem um trabalho com psicólogos, os homens, tem uma cidade que eu assisti os homens que agridem as mulheres, eles passam por tratamento psicológico pra resolver isso. Acho que deveria ter isso em mais lugares, porque é uma coisa também que as pessoas desabafam, porque talvez tem um problema entre a gente que sofreu uma violência também (Ernestina, RC).

\section{Reflexões finais}

Ao analisar os discursos dos (as) participantes foi possível reconstruir os direitos e responsabilidades dos sujeitos que ali estavam, bem como de suas redes de relações, identificando, a partir daí, as distintas versões do mundo que coexistem nos discursos emitidos (Parker, 1996). Os resultados da pesquisa aqui realizada dialogam com a literatura produzida na área, que demonstra como as violências muitas vezes surgem justamente diante das indagações que são colocadas frente às regulações de gênero e cujas permutações, como bem demonstra Butler (2005), têm altos custos para sujeitas e sujeitos. Custos esses que podem redundar na disciplinarização de mulheres como forma de normali- zá-las e silenciá-las ou, ainda, com a emergência de uma posição também violenta por parte de algumas, na tentativa de não serem violentadas ou de acabarem com os abusos cometidos contra elas.

Além disso, a procura por direitos por parte da plateia demonstra o quanto as mulheres são vistas como sujeitos de direitos e a violência como algo que não deve ser sustentado. Outras formas de lidar com o problema, como a abertura para a discussão junto à sociedade sobre feminilidades e masculinidades quase não foram acessadas. Alguns desses resultados mostram que o cenário das políticas para o enfrentamento da violência, por meio de sua ampla divulgação, acaba por influenciar opiniões, construir discursos e práticas junto à população, permitindo que esta reconstrua seus posicionamentos a partir daí.

Ademais, as implicações e desenvolvimento do estudo ora realizado para a Psicologia podem ser resumidas na tentativa de considerar a violência contra as mulheres em uma perspectiva que leve em consideração os aspectos políticos da existência por meio da análise de eixos de poder e diferenciação que contribuem para que ela seja vivenciada de maneiras específicas por cada mulher, dependendo do lugar que ela ocupa na sociedade.

Foi possível também assinalar que essa disciplina precisa respaldar-se em um amplo conhecimento para lidar com esse tema, não podendo estar encerrada em explicações reducionistas, individualizadas e que revitimizam as mulheres. São necessárias intervenções que garantam a interdisciplinaridade e que procure, ao mesmo tempo, elucidar qual o papel que o (a) psicólogo (a) pode adotar nas redes de enfrentamento à violência, o objetivo de sua atuação, a importância de sua escuta e intervenção e seu posicionamento dentro desse campo de atuação.

O presente estudo também permitiu a compreensão da importância da historicidade na produção das posições que puderam ser 
visualizadas nas práticas discursivas da plateia para a qual o esquete foi apresentado. Nesse ponto, é possível refletir que o estudo empírico realizado permitiu que se acessassem tais discursos, demonstrando que o teatro fórum é um dispositivo que produz ações muitas vezes contraditórias por parte de quem assiste ao espetáculo, pois pode ser que a mesma pessoa que se levanta e assume o lugar do (a) protagonista, transformando-se em espect-ator/atriz e defendendo-o(a), é aquela que, nesse mesmo lugar, pode, implicitamente, acusá-lo(a) ou contribuir para a manutenção das opressões vivenciadas.

Pensando no uso dessa metodologia dentro de pesquisas participativas ou interventivas nas universidades, faz-se necessário criar um mecanismo que provoque a continuidade dos encontros quando o objetivo é levar o produto (peça-fórum) para as pessoas, tentando garantir uma problematização maior sobre o tema que será debatido: como mostrar as contradições contidas nos discursos da plateia e o quanto elas contribuem para a manutenção do status quo? Os próprio apontamentos do(a) curinga durante o fórum conseguem evidenciá-las? É possível provocar fissuras nas formações discursivas da plateia, de forma a não apenas levantar uma profusão de ideias, mas também permitir a reflexão sobre seus posicionamentos e a consequente responsabilidade que se posicionar implica? Uma única apresentação de uma peça-fórum permite esse tipo de ação? Ou seria o objetivo de uma peça-fórum apenas disparar opiniões, tal como um filme ou outro dispositivo semelhante o fariam? Se for isso apenas, por que escolher o TF e não um filme ou uma palestra? Ou, diferente de assistir um filme ou uma palestra, passivamente, o corpo ativado durante o fórum é ele também produtor de novos significados e, se sim, como o (a) pesquisador (a) pode inscrever e inaugurar narrativas sobre esse corpo mobilizado, acionado e em rede com outros corpos?

Parece-me, então, que da apresentação de uma peça-fórum devem resultar várias outras intervenções que desvelem o quanto a própria plateia contribuiria para situações como as apresentadas pela protagonista, neste caso, a violência no interior de uma parceria afetiva e discussões sobre poder devem fazer parte desse momento. Cabe acentuar que parece mais enriquecedor, quando isso é possível, que a peça seja construída com pessoas da própria população e que estas possam levar o espetáculo para a comunidade em geral.

Esse processo de construção coletiva, de ensaios e apresentações, de diálogo com pessoas de diferentes segmentos populacionais, poderia permitir um reposicionamento significativo diante do tema, ao menos por parte dos (as) integrantes do processo de construção da peça. O caráter processual de uma construção de uma peça de teatro fórum, portanto, não deve ser perdido de vista em nenhum momento da pesquisa. Chamo a atenção para isso por acreditar que uma produção vinda da população pode ser mais impactante do que uma produção feita e apresentada por pessoas da própria universidade. Nesse sentido o Teatro do (a) Oprimido (a) seria uma metodologia inovadora dentro da universidade, por permitir o desenvolvimento de um processo grupal de desconstrução e reconstrução a respeito de um determinado assunto, destinado a atingir não apenas o grupo pesquisado, mas também outros estratos da sociedade.

Seguindo essa linha de raciocínio, é possível pensar que esse dispositivo, diferente de uma entrevista ou grupo focal, por exemplo, tem a possibilidade de alcançar um número significativo de pessoas, além daquelas que estiverem fazendo parte do processo de elaboração da peça-fórum. Ao levá-lo para as demais parcelas da população, aposta-se na multiplicidade e disseminação do debate, realizado pela comunidade e para a comunidade, do modo previsto por Boal. Faz-se, assim, com que as próprias pessoas que vivenciam as diversas realidades de opressão social, uma vez tendo tomado consciência delas, possam comunicar para outras pessoas, 
por meio de sua própria linguagem, sua insatisfação diante disso.

Nesse sentido, o TF é mobilizador de ações, criador de conscientização, revelador de novas possibilidades discursivas. Claro está que, consoante a isso, é necessário que se acompanhe as decisões políticas que afetam diretamente o tema estudado pelo grupo, tarefa primordial para o (a) curinga, que deve fornecer todo o material disponível e atualizado sobre o assunto que está sendo investigado, o que significa iniciar um sério estudo, caso contrário, o trabalho perde sua veracidade e carga política, não podendo contribuir com debates importantes que estão acontecendo na sociedade.

Além disso, acredito que uma contribuição necessária para o estudo e aprofundamento dessa ferramenta resida na análise crítica de seus binarismos - opressor (a) versus oprimido (a) - e o quanto eles servem para auxiliar na manutenção das regulações de gênero (no caso específico da violência contra as mulheres). É preciso pesquisar junto aos grupos que realizam esse tipo de trabalho se estes estão levando em consideração discussões como as que foram realizadas nesta pesquisa, estando atentos (as) para o modo como a plateia reage às personagens que são apresentadas e se o gênero tem sido tratado em sua dimensão relacional. Caso contrário, há que se ter investigações sobre o modo como esse tipo de debate tem sido veiculado e se tem, de fato, provocado transformações nas pessoas e agido como um "modelo para a ação futura" contribuindo para a reflexão não apenas de uma sociedade sem violência mas também de uma mulheres e homens mais emancipados.

\section{Érika Cecília Soares Oliveira}

Doutora em Psicologia e Sociedade pela Universidade Estadual Paulista, São Paulo - SP. Brasil

E-mail: oliverik_br@yahoo.com.br

Endereço para envio de correspondência:

Rua Ricardo Pinto, 195 apartamento 13 - Aparecida. CEP: 11035-171. Santos - SP. Brasil

Recebido 27/03/2013, Aprovado 29/08/2013. 


\section{Referências}

Azerêdo, S. M. da M. (2002). O político, o público e a alteridade como desafios para a Psicologia. Psicologia: Ciência e Profissão. Brasília, 22(4), 14-23. doi: 10.1590/S141498932002000400003

Bandeira, L. (2009). Três décadas de resistência feminista contra o sexismo e a violência feminina no Brasil: 1976 a 2006. Sociedade e Estado. Brasília, 24(2), 401-438. doi: 10.1590/S0102-69922009000200004.

Barsted, L. L. (2011). O progresso das mulheres no enfrentamento da violência. In L. L. Barsted, \& J. Pitanguy. O progresso das mulheres no Brasil 2003-2010 (pp. 346-381). Rio de Janeiro: CEPIA; Brasília: ONU Mulheres.

Beiras, A., Moraes, M., Alencar-Rodrigues, \& Cantera, L. M. (2012). Políticas e leis sobre violência de gênero: reflexões críticas. Psicologia \& Sociedade. Belo Horizonte, 24(1), 36-45. doi: 10.1590/S0102-71822012000100005

Boal, A. (2005). Teatro do Oprimido e outras poéticas políticas. Rio de Janeiro: Civilização Brasileira.

Butler, J. (2002). Criticamente subversiva. In Jiménez, R. M. (Org.). Sexualidades transgresoras: una antologia de estúdios queer (pp. 55-79). Barcelona: Editorial Icaria.

Butler, J. (2005). Regulaciones de género. La ventana, 23, 7-35. Recuperado de http://www.redalyc.org/articulo.oa?id $=88402303$

Butler, J. (2006). Vida precaria: el poder del duelo y la violência. Buenos Aires: Paidós.

Butler, J. (2010). Corpos que pesam: sobre os limites discursivos do "sexo". In Louro, G. L. O corpo educado: pedagogias da sexualidade (pp. 151-172). Belo Horizonte, MG: Autêntica Editora.

Brah, A. (2004). Diferencia, diversidad y diferenciación. In B. Hooks, A. Brah, C. Sandoval, G. Anzaldúa, A. L. Morales, K. K. Bhavnani, M. Coulson, M. J. Alexander, \& C. T. Mohanty. Otras inapropiables: feminismos desde las fronteras. (pp. 107-136). Madrid: Editorial Traficantes de Sueños.

Debert, G. G., \& Gregori, M. F. (2008). Violência e gênero: novas propostas, velhos dilemas. Revista Brasileira de Ciências Sociais. São Paulo, 23(66), 165-211. doi: 10.1590/S010269092008000100011
Dias, M. B. (2006). A violência doméstica na Justiça. Direito e Democracia: revista do Centro de Ciências Jurídicas/Universidade Luterana do Brasil, Canoas: Ed. ULBRA, 7( 2), 271280. Recuperado de http://www.ulbra.br/direito/files/direito-e-democraciav7n2.pdf?26082013

D’Oliveira, A. F. P. L. (2000). Violência de gênero, necessidades de saúde e uso de serviços em atenção primária. Tese doutorado, Faculdade de Medicina, Universidade de São Paulo. São Paulo.

Foucault, M. (1973). A verdade e as formas jurídicas. Rio de Janeiro: NAU Editora.

Foucault, M. (1997). A ordem do discurso. Portugal: Relógio D’Água Editores.

Foucault, M. (2008). A arqueologia do saber. Rio de Janeiro: Forense Universitária, (Trabalho original publicado em 1969).

Foucault, M. (2012). Verdade e o poder. In M. Foucault. Microfísica do poder. (pp. 1-14). Rio de Janeiro: Edições Graal (Trabalho original publicado em 1979).

Freire, N. (2011). Mulheres e poder uma relação delicada? In Barsted, L. L., \& Pitanguy, J. O progresso das mulheres no Brasil 2003-2010 (pp. 137-139). Rio de Janeiro: CEPIA; Brasília, DF: ONU Mulheres.

Haraway, D. (1995). Saberes localizados: a questão da ciência para o feminismo e o privilégio da perspectiva parcial. Cadernos Pagu. Campinas, 5, 7-41. Recuperado de file://C:/Users/familia/Downloads/cadpagu_1995_5_2_HARAWAY.pdf

Haraway, D. (2000). Manifesto ciborgue: ciência, tecnologia e feminismo-socialista no final do século XX. In T. T. Silva. Antropologia do ciborgue: as vertigens do pós-humano. (pp. 38129). Belo Horizonte, MG: Autêntica.

Haraway, D., \& Azerêdo, S. M. da M. (2011). Companhias multiespécies nas naturezaculturas: uma conversa entre Donna Haraway e Sandra Azerêdo. In M. E. Maciel (Org.), Pensar/escrever o animal: ensaios de zoopoética e biopolítica. (pp. 389-417). Florianópolis, SC: Editora da UFSC. 
Hooks, B. (2004). Mujeres negras: dar forma a la teoría feminista. In B. Hooks, A. Brah, C. Sandoval, G. Anzaldúa, A. L. Morales, K. K. Bhavnani, M. Coulson, M. J. Alexander, \& C. T. Mohanty. Otras inapropiables: feminismos desde las fronteras. (pp. 33-50).Madrid: Editorial Traficantes de Sueños.

Iñiguez, L. (2005a). A linguagem nas ciências sociais: fundamentos, conceitos e modelos. In

L. Iñiguez. Manual de análise do discurso em ciências sociais (pp. 50-104). Petrópolis, RJ: Vozes.

Iñiguez, L. (2005b). A análise do discurso nas ciências sociais: variedades, traduções e práticas. In .L. Iñiguez Manual de análise do discurso em ciências sociais (pp. 105-160). Petrópolis, RJ: Vozes.

Llombart, M. P. (1993). Mujer, relaciones de género y discurso. Revista de Psicología Social. 8(2), 201-215. Recuperado de file:///C:/Users/familia/Downloads/Dialnet-MujerRelacionesDeGeneroYDiscurso-111788.pdf

Maciel, D. A. (2011). Ação coletiva, mobilização do direito e instituições políticas: o caso da campanha da Lei Maria da Penha. Revista Brasileira de Ciências da Sociais, São Paulo, 26(77), 97-111. doi: 10.1590/S010269092011000300010

Medrado, B., \& Méllo, R. P. (2008). Posicionamentos críticos e éticos sobre a violência contra a mulher. Psicologia \& Sociedade. Belo Horizonte, 20(Spe.), 78-86. doi: 10.1590/S0102-71822008000400011

Meneghel, S. N., Bairros, F., Mueller, B., Monteiro, D., Oliveira, L. P., \& Collaziol, M. E. (2011). Rotas críticas de mulheres em situação de violência: depoimentos de mulheres e operadores em Porto Alegre, Rio Grande do Sul State, Brazil. Cad. Saúde Pública. Rio de Janeiro, 27(4), 743-752. doi: 10.1590/S0102311X2011000400013
Menicucci , E. (2014, 07 ago.). Avanços da Lei Maria da Penha são destacados por ministra na 8a Jornada do CNJ. In Jornada de TrabaIhos da Lei Maria da Penha, 8, Brasília, DF: Conselho Nacional de Justica.

Oliveira, K. L. C. de \& Gomes, R. (2011). Homens e violência conjugal: uma análise de estudos brasileiros. Ciência \& Saúde Coletiva. Rio de Janeiro, 16(5), 2401-2413. doi: 10.1590/S141381232011000500009

Parker, I. (1996). Discurso, cultura y poder en la vida cotidiana. In Gordo-López, A. J., \& Linaza, J. (Eds.). Psicología, discurso y poder: metodologias cualitativas, perspectivas críticas (pp. 7992). Madrid: Visor.

Pougy, L. G. (2010). Desafios políticos em tempos de Lei Maria da Penha. Rev. Katálysis, Florianópolis, 13(1), 76-85. doi: 10.1590/S141449802010000100009

Santos, C. M. (2008). Da delegacia da mulher à Lei Maria da Penha: lutas feministas e políticas públicas sobre violência contra mulheres no Brasil. Oficina do CES, Centro de Estudos Sociais, 301, 1-38. Recuperado de http://www.ces.uc.pt/publicacoes/oficina/ficheiros/301.pdf

Scott, J. W. (1995). Gênero: uma categoria útil de análise histórica. Educação e Realidade, Porto Alegre, 2(20), 71-99.

Willig, C. (2008). Foucauldian discourse analysis. In: C. Willig. Introducing qualitative research in psychology (pp. 112-131). London: Open University Press. 
Errata 1. Na edição 34.3, página 555, cujo artigo é "Eu Também sei atirar"! Reflexões sobre a Violência contra as Mulheres e Metodologias Estético-Políticas, a imagem de ilustração foi escolha exclusiva do periódico e não da autora do artigo Érika Cecília Soares Oliveira. 